

\title{
Bridging the gap between science, service and politics - PhD Student representation at universities
}

\author{
Lukas Peintner ${ }^{1,2}$
}

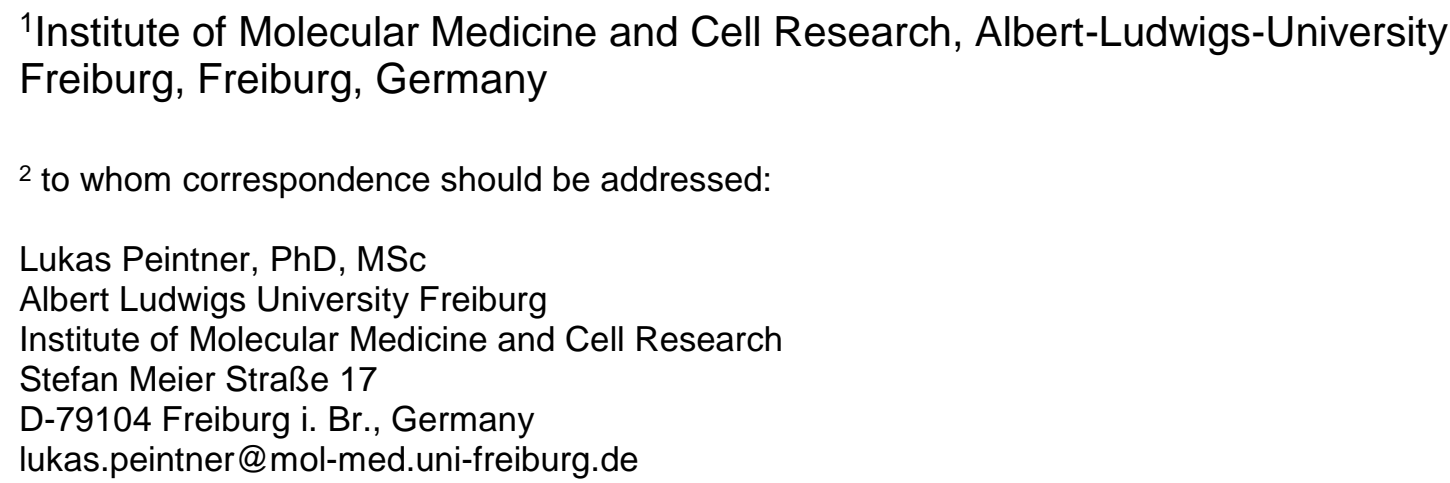

A PhD student is lonely and scared. There is this vast body of university, long lists of curricula and a wobbling bureaucracy on the one hand and a small insignificant graduate student, who is just interested in doing science. Since graduate students are used to fight as a lone warrior they tend to forget that there are students at their university that face the exact same problems as they do, especially when it comes to understand the hierarchy of the administrative machinery or to negotiate another funded year with their PI.

This is the point when $\mathrm{PhD}$ student representation comes into focus. Contrary to undergraduate representation, service for $\mathrm{PhD}$ students demands more than simply showing freshmen the path to the next lecture hall. PhD students are advanced in their studies and don't struggle with lectures or exams. But they are naive when it comes to funding, organizing conference trips, discussing their case to the graduate research committee and finish their studies within their desired timeframe.

PhD student representation exists at many universities, often founded by different means. In some universities student representations form spontaneously, initiated by enthusiastic students, sometimes with the help of the chancellor. In other universities, student representations are part of an obligatory political students union, which often gets funded via compulsory study fees. Both systems have in common that they are run by zealous, mostly voluntarily working students. This ensures, that the representative is still close to the $\mathrm{PhD}$ student and better understands their problems and needs. 
The task of a PhD student representation is a tricky one. Representatives try to bridge the gap between science, service and politics for the students. By doing so they can contribute significantly to the social and scientific life of a university and over the years actively create the environment for a PhD student.

Over the last years the $\mathrm{PhD}$ representation at my former university became an accepted organizer of scientific events due to the work of many motivated students. For instance once a year all $\mathrm{PhD}$ students from all the various fields got invited to present their posters and discuss their work to friends, peers and Pls. Invitation of key note lecture speakers and representatives from the industry and European/international research consortiums made a day like this a memorable event for PhD students. The ever growing number of participating students and also the fact that many students recommend key note lecture speakers during the year is a clear indication, that events organized by students for students are accepted by the community of a university. Organization of such events needs a committed team, willing to work many extra hours while negotiate with the university, organizing a poster jury, bargaining deals with catering companies and inviting and hosting external speakers. Considerable amount of manpower is needed during setup of the day itself (e.g. poster walls and tables, cleanup afterwards). Money is a crucial factor in the organization of meetings. The university and some doctoral colleges are usually willing to provide some funding, but due to the notorious budged crisis of universities it won't be sufficient to run this event. Companies in the life science sector are normally excited to fund events like this with little money, often asking if it's possible to set up a promotional stand at the meeting. This makes a $\mathrm{PhD}$ science day even more professionally looking! To successfully address potential sponsors, a detailed plan about the event with a schedule and expected numbers of attendees needs to be provided. However, exact book-keeping is mandatory to avoid eventual problems with the sponsors or even the fiscal authorities.

Beside this big event we also organized small group methods seminars over the last years. Initiated by a suggestion by several students, collegians from various fields were gathering and presented a fancy method they were employing in their lab. In a very relaxed environment, fueled by free pizza and beer ad libitum, many new research collaborations were made between the participants.

But not only dead serious science is part of a student's life at the university. Average sized universities have up to several hundred PhD students dispersed over the 
campus. Bringing them together can either be achieved by scientific events but also by organizing social events such a PhD - Barbecue during summer months or pub crawls for first term students at the start of a semester. Interestingly, however, we made the experience that $\mathrm{PhD}$ students didn't accept the invitation to social events as much as they did it for our scientific activities. As a rule of thumb we figured out, that usually $10 \%$ of all the invited persons attend this kind of parties, while for our scientific events up to $40 \%$ of all the invitees accepted the call.

So far I only talked about big crowd gatherings. Actually the central task of a PhD student representation is to provide service about every days problems of a $\mathrm{PhD}$ student. Although many universities in Europe claim to be international in order to attract bright people from all over the world, they often struggle with translating all the necessary information for $\mathrm{PhD}$ students into English and provide it on their homepage. Furthermore, bureaucracies of universities are usually big non-transparent monsters and a single student will have its fair share of despair when he tries to gain information about a particular concern. That is the moment when a helpless $\mathrm{PhD}$ student should call his representative. Either via E-mail or in the next door cafeteria most problems can be solved in no time or at least the representative can drop a few names which might know the proper answer to ones question.

In Europe the standard language in doctoral colleges is English. However, outside of the university in non-English speaking countries people often fail to communicate in English to international students. This leads to communication difficulties in many situations such as talking to landlords or doing paperwork for the city council administration. Local student representatives are happy to be a friend in need and help with translation and paperwork - just bribe them with some cookies.

In numerous countries student representations are the political voice for students and imposed by national law. Regular (e.g. biannual) democratic elections give the possibility to students to vote for their political representation. Elected and inaugurated student-representatives are then allowed to take part in the policy making process of a university. In doing this successfully, student representatives are contingent upon input from their fellow students. Communication is crucial to make upcoming changes in the universities policy visible to the student and students should be encouraged to propose their ideas on hot topics to their representatives. It's then their duty to discuss those issues to either the rectorate or the PI faculty. Regular auditions of the student representatives to the chancellor and the faculty creates an ambience of reliance and 
this eases the transport of ideas and suggestions for improvement. Even when the topics are very controversially discussed, input from the students is usually welcomed by the executive branches of a university since it often helps to improve the quality of the life on campus and might also has positive influence on various international and national university rankings.

Summarized, times as a PhD Student are tough. But when some students gather and try to improve the environment students are working both sides, the student and the university, will be grateful about the efforts. A student representation can improve the scientific interaction between various labs, it can help students with their everyday struggle to survive the bureaucracy and it can act as a mediator between the interests of a student on the one hand and the university executive branch on the other hand. For the representatives itself this job is mostly a welcomed distraction from the everyday bench side problems and a perfect training of additional skills needed to pursue a career in science usually not taught in a university graduate program. 